\title{
低温焼結フェライトの線邆張係数の制御
}

\author{
中野 敦之放，青木 卓也蚆，木村修的

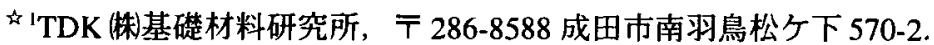 \\ 4 2 湘南工科大学工学部マテリアル工学科, テ 251-8511 藤沢市辻堂西海岸 1-1-25.
}

\section{Control of Thermal Expansion Coefficient of Low Temperature Sintering Ferrites}

\author{
Atsuyuki Nakano ${ }^{\text {h1 }}$, Takuya Aoki ${ }^{\text {t } 1}$ and Osamu Kimura \\ 'Materials Research Center, TDK Corporation, 570-2 Matsugashita Minamihatori, Narita 286-8588. \\ ${ }^{\star 2}$ Shonan Institute of Technology, 1-1-25 Nisikaigan Tujido, Fujisawa 251-8511.
}

Received April 26, 2002

\begin{abstract}
SYNOPSIS
A one-chip type transformer is produced as an MHD (Multilayer-Hybrid-Circuit-Device) using a multilayer technology and it contributes to miniaturize of a DC/DC converter. In order to get high efficiency of this transformer, it is needed to reduce the residual magnetic flux neighborhoods of internal electrode. Therefore, the internal electrode is needed to cover with nonmagnetic oxide completely in MHD. However, the discrepancy of thermal expansion coefficient between these materials produces internal stress which causes a degradation of magnetic properties and internal cracks in the worst case. Many studies were reported about internal stress effect comes from the internal Ag electrode to produce high performance multilayer chip inductor. In this paper, a study about the thermal expansion coefficient of ferrites was performed to reduce the thermal expansion coefficient discrepancy between NiCuZn ferrite and $\mathrm{CuZn}$ ferrite. It was found that the thermal expansion coefficient was able to control by ferrite compositions and degree of raw materials mixing. And it was thought that the thermal expansion coefficient was affected by ferrite compositions as well as thermal vibration which was caused from imperfect match at the interface between a spinel structure and a residual unreacted oxide materials in sintered ferrite body.
\end{abstract}

KEY WORDS

$\mathrm{NiCuZn}$ ferrites, thermal expansion coefficient, multilayer ferrite chip components, stress

\section{1 緒言}

近年, 電子回路のデジタル化に伴い電子機器の軽薄化の流 れは急速に加速されている、これに伴い，基盤上の表面実装 も更なる高密度化が求められ, 受動部品のコンデンサやイン ダクタもその高密度実装の要求に応えるため, 表面実装夕イ プの小型積層型チップ部品に形を変え電子機器に多く用いら れている.

積層型チップインダクタは，形状的なダウンサイジングだ けではなく，アレイ化や誘電体との複合化などの流れも急激 に加速している. また, Fig.1 に示す積層型混成集積回路素子 (MHD: Multilayer-Hybrid-Circuit-Device)はその積層技術を用い てトランスを 1 チップ化し，その上に機能部品(IC等)を搭載 することでDCDCコンバータの小型化に貢献している.この 皘層型トランスの効率を向上させるため, この厚膜印刷積層 技術を用いて内部導体を 3 次元的に非磁性材料 $(\mathrm{Zn}$ フェライ
ト)で覆う構造にすることで, 電極周辺の小さな磁束を抑制し 磁性体に大きな磁束を通すことが可能となり飛躍的な効率向 上が図られている ${ }^{1.2)}$.

この場合, 積層型トランス内部では, 磁性材料の低温焼結 $\mathrm{NiCuZn}$ フェライトと非磁性材料の低温焼結 $\mathrm{CuZn}$ フェライト との線膨張係数の違いから内部応力が発生し, 磁気特性の少 化や，最悪の場合，内部クラックが生じる. 内部応力に関し ては，これまでも皘層型チップインダクタの磁気特性向上を 目的にAg内部導体からの応力抑制技術に関して多くの研究が

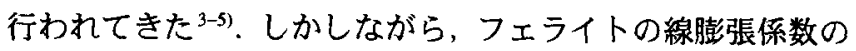
制御に関しては殆ど知見がなかった.

そこで, 本研究は低温焼結 $\mathrm{NiCuZn}$ フェライトと低温焼結 $\mathrm{CuZn}$ フエライトの線膨張係数の差を減少させる目的とし, 両 材料の線膨張係数制御について検討を行ったのでその結果を 報告する。 

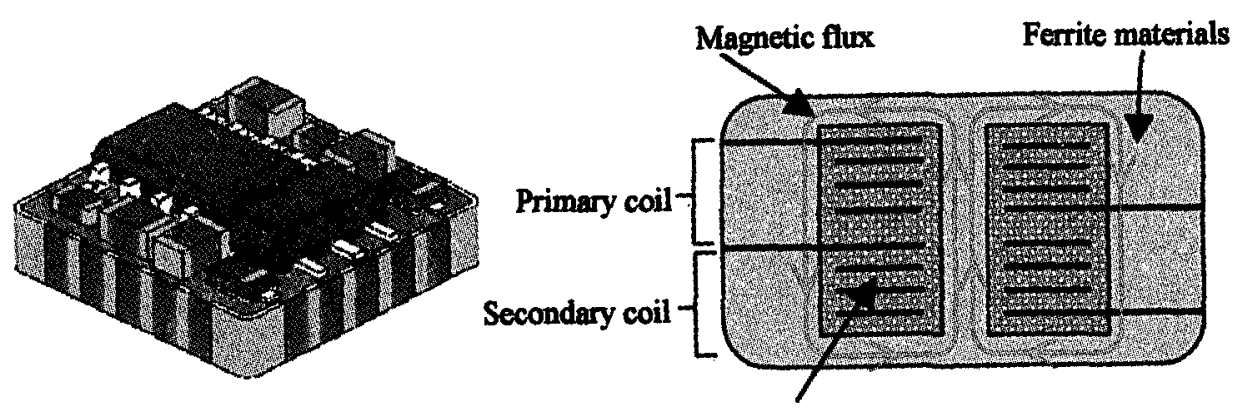

Non-magnetic ferrite materials

Fig.1 Structure of Multilayer Hybrid Circuit Device.

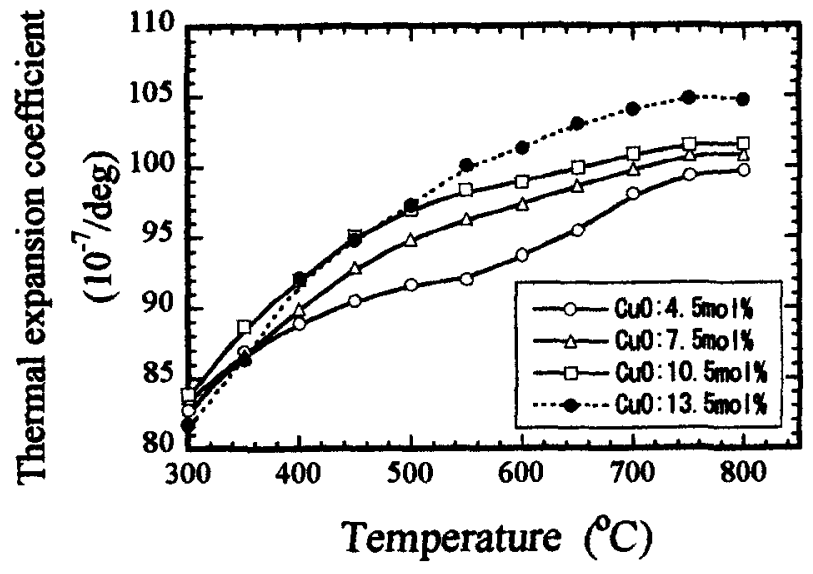

Fig.2 Effect of amount of $\mathrm{CuO}$ on thermal expansion coefficient of CuZn ferrites.

\section{2 試料及び実験方法}

$\mathrm{NiCuZn}$ フェライトと $\mathrm{Zn}$ フェライトは同様な湿式粉末冶金 法で調製した。市販の各原料 $\mathrm{Fe}_{2} \mathrm{O}_{3}, \mathrm{NiO}, \mathrm{CuO}, \mathrm{ZnO}$ を所定の 比に秤量した後, 鋼鉄製ボールミルを用いて $1 \sim 16$ 時間湿式 混合し乾燥した。この混合条件は，4インチミルポットに材料： $300 \mathrm{~g}, 1 / 2$ インチスチールボール : $200 \mathrm{~g}, 1 / 8$ インチスチール ボール : $600 \mathrm{~g}$, 純水: $600 \mathrm{~g}$ とした. 得られた混合粉は, 両フエ ライトとも $720^{\circ} \mathrm{C} て ゙ 10$ 時間の仮焼を施した．仮焼粉は比表面 皘 : $8 \mathrm{~m}^{2} / \mathrm{g}$ になるまで鋼鉄製ボールミルで湿式粉䂶し乾燥を 行った.これらの調製方法によって両材料も $900^{\circ} \mathrm{C}$ 以下でも 緻密に焼結出来る低温焼結フェライトになる.用いた組成は, $\mathrm{CuZn}$ フェライトの検討では, $\mathrm{Fe}_{2} \mathrm{O}_{3}: 46 \sim 48 \mathrm{~mol} \%, \mathrm{CuO}: 4.5$ $\sim 10.5 \mathrm{~mol} \%, \mathrm{ZnO}: 39.5 \sim 42.5 \mathrm{~mol} \%$ とした. $\mathrm{NiCuZn}$ フェラ イトの検討では, $\mathrm{Fe}_{2} \mathrm{O}_{3}: 48 \sim 49 \mathrm{~mol} \%$, $\mathrm{NiO}: 12 \sim 36 \mathrm{~mol} \%$, $\mathrm{CuO}: 8 \sim 10 \mathrm{~mol} \%$, $\mathrm{ZnO}: 8 \sim 32 \mathrm{~mol} \%$ とした.

得られた粉体はPVA6\%水溶液 $10 \mathrm{wt} \%$ を添加し造粒した. そ の顆粒は線膨張係数測定用に $10 \times 10 \times 40 \mathrm{~mm}$ の長方体に成型 し，大気中で $890^{\circ} \mathrm{C}$ の温度で焼成した，また，磁気特性測定 のために T5-トロイダルを成型し，加圧実験用には角型トロ イダルを成形し $890^{\circ} \mathrm{C}$ の温度で焼成した．線膨張係数測定用 試料は, TMA8310 (Rigaku 社) 用いて $50^{\circ} \mathrm{C}$ を基準として 100

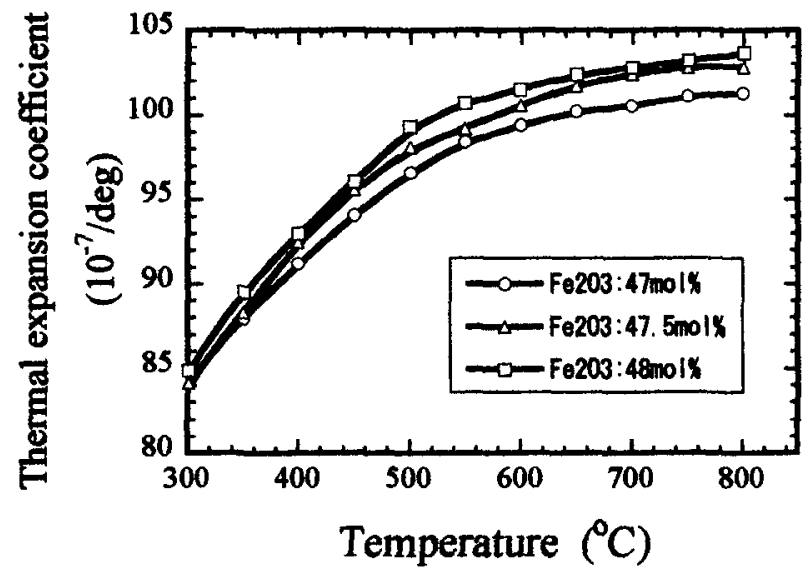

Fig.3 Effect of amount of $\mathrm{Fe}_{2} \mathrm{O}_{3}$ on thermal expansion coefficient of CuZn ferrites.

〜 $850^{\circ} \mathrm{C}$ の線膨張係数を測定した. トロイダル試料は LCR メータ (HP4192A) を用いて初透磁率 $(\mu \mathrm{i})$ を測定した. また, 原 料の混合度はEPMAを用いて解析を行った.

\section{3 結果および考察}

\section{1 組成の影響}

先ず, 電極周辺に積首される非磁性フェライトの低温焼結 $\mathrm{CuZn}$ フェライトの線膨張係数に及ぼす $\mathrm{CuO}$ の影響を調べた 結果を Fig.2 に示す. $\mathrm{Fe}_{2} \mathrm{O}_{3}$ 租成を $47 \mathrm{~mol} \%$ とし, $\mathrm{CuO}$ 量を 4.5 〜 $13.5 \mathrm{~mol} \%$ と增加させ, 残量を $\mathrm{ZnO}$ とすることでフェライ トの線膨張係数は増加した. また, $\mathrm{CuO}: 10.5 \mathrm{~mol} \%, \mathrm{ZnO}: 41.5$ $\sim 42.5 \mathrm{~mol} \%$ の組成において $\mathrm{Fe}_{2} \mathrm{O}_{3}$ を 47, 47.5, $48 \mathrm{~mol} \%$ と増加 させ, 線膨張係数に及ぼす $\mathrm{Fe}_{2} \mathrm{O}_{3}$ の影響を調べを調べた Fig.3 に示す. $\mathrm{Fe}_{2} \mathrm{O}_{3}$ を増加させることでもフェライトの線膨張係数 は增大した．これは， $\mathrm{ZnO}$ の線膨張係数に比べ $\mathrm{CuO} や \mathrm{Fe}_{2} \mathrm{O}_{3}$ の線膨張係数が大きいため $\mathrm{CuO}$ や $\mathrm{Fe}_{2} \mathrm{O}_{3}$ の固溶限を増加させ ることでフェライトの線膨張係数が増大したと考えられる. 尚,この組成検討範囲のフェライトはキュリー温度が $-25^{\circ} \mathrm{C}$ 以下であるために, 電子部品に要求される温度特性範囲 $(-25$ $\sim 120^{\circ} \mathrm{C}$ )では磁気特性を示さず, 積層部品用非磁性材料とし て使用できる. 
次に, 磁性材料の低温焼結NiCuZn フェライトの組成と線膨 張係数の関係を調べた. 用いた組成は, $\mathrm{Fe}_{2} \mathrm{O}_{3}: 48 \mathrm{~mol} \%, \mathrm{NiO}$ : $12 \sim 36 \mathrm{~mol} \%, \mathrm{CuO}: 8 \mathrm{~mol} \%, \mathrm{ZnO}: 8 \sim 32 \mathrm{~mol} \%$ とした.この 場合, $\mathrm{NiCuZn}$ フェライトの線膨張係数の値を $\mathrm{CuZn}$ フェライ トの線膨張係数の值に近づけることが目的となる．線膨張係 数に及ぼす組成の影響を Fig.4 に示す．図から分かるように $\mathrm{ZnO}$ 量を増加させて透磁率が高めたフェライトほど線膨張係 数が低下することが分かる.これらの結果から, NiCuZnフェ ライト組成の $\mathrm{ZnO}$ 量を増加させ, また, $\mathrm{CuZn}$ フェライト組成 の $\mathrm{CuO}$ 量及び $\mathrm{Fe}_{2} \mathrm{O}_{3}$ 量を増加させることで両材料の線膨張係 数差を小さくさせることが得られた。

\section{2 原料混合度の影響}

低温焼結フェライトの場合, 原料の混合度が磁気特性や焼 成時の緻密化に大きく影響する ${ }^{5)}$. そこで, 原料の混合度が線 膨張係数などの物理定数にも影響があるのかを調べ, CuZn フェライトの線膨張係数に及ぼす原料混合時間の影響をFig.5 に示す.この検討では, $\mathrm{Fe}_{2} \mathrm{O}_{3}: 46 \mathrm{~mol} \%, \mathrm{CuO}: 10 \mathrm{~mol} \%, \mathrm{ZnO}$ : $44 \mathrm{~mol} \%$ の組成を用いた.図から分かるように原料混合時間の 増加に伴い $\mathrm{CuZn}$ フェライトの線膨張係数は増大した。 そこ

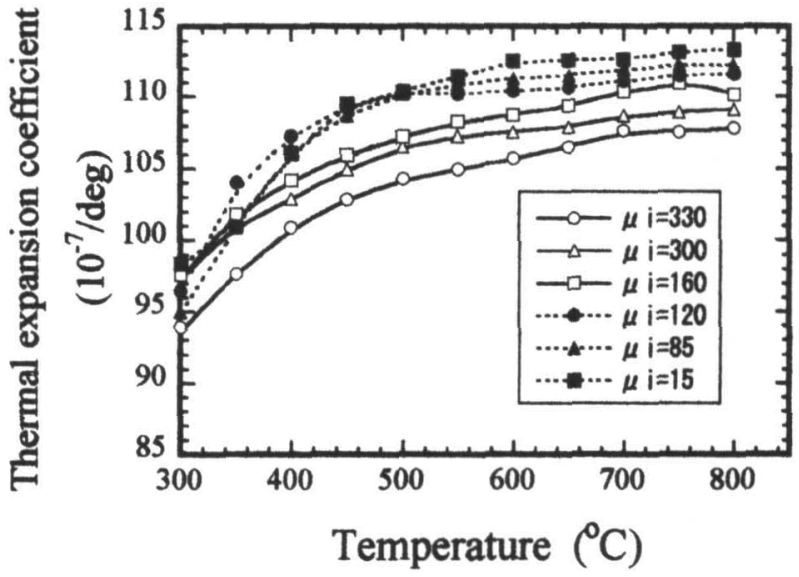

Fig.4 Effect of compos ion on thermal expansion coefficient of $\mathrm{NiCuZn}$ ferrites.

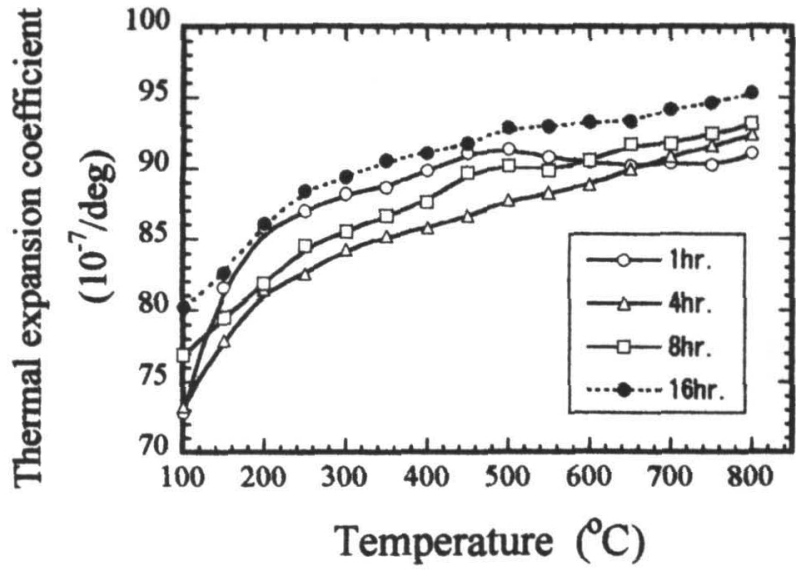

Fig.5 Effect of mixing time on thermal expansion coefficient of $\mathrm{CuZn}$ ferrites.
で, NiCuZn フェライトも同様の実験を行った. 用いた組成は $\mathrm{Fe}_{2} \mathrm{O}_{3}: 49 \mathrm{~mol} \%$, NiO: $12 \mathrm{~mol} \%$, $\mathrm{CuO}: 10 \mathrm{~mol} \%, \mathrm{ZnO}: 29 \mathrm{~mol} \%$ である. Fig.6に NiCuZn フェライトの線膨張係数に及ぼす原

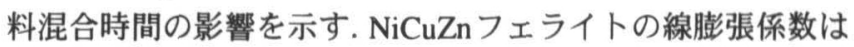
原料混合時間の増加に伴い逆に低下した。この線膨張係数が 低下することは, Fig.4に示したようにフェライト中の $\mathrm{ZnO}$ 量 が増加した場合の線膨張係数変化と同じ傾向である. しかし ながら,この結果はCuZnフェライトの線膨張係数の変化と正 反対の挙動を示した.

そこで, 各試料について原料の混合度合いを調べるために EPMAを用いて各原料の分散度を解析した. NiCuZnフェライ トのEPMA解析結果を Fig.7に示す. それぞれの原料が混合時 間の増加に伴い分散されていることが分かる.この結果をグ

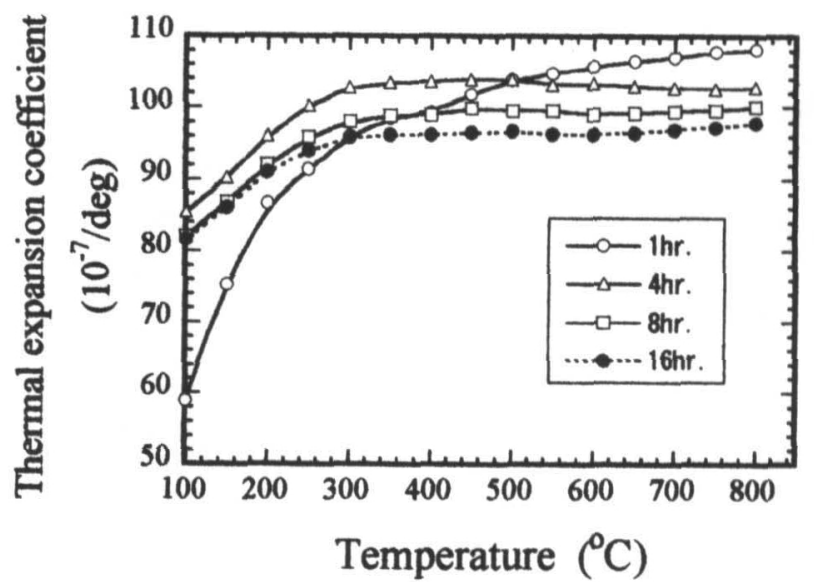

Fig.6 Effect of mixing time on thermal expansion coefficient of $\mathrm{NiCuZn}$ ferrites.

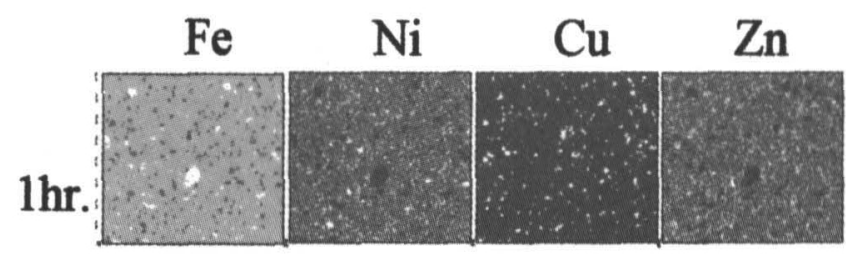

4hr.

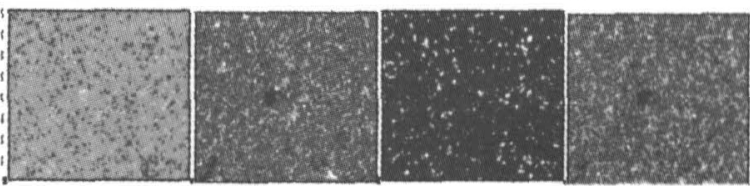

$8 \mathrm{hr}$.

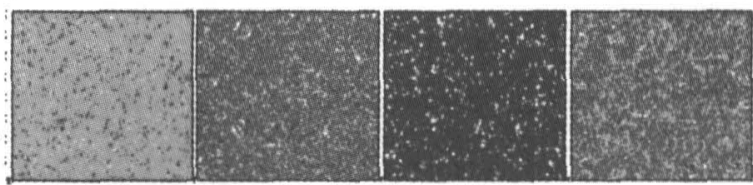

$16 \mathrm{hr}$

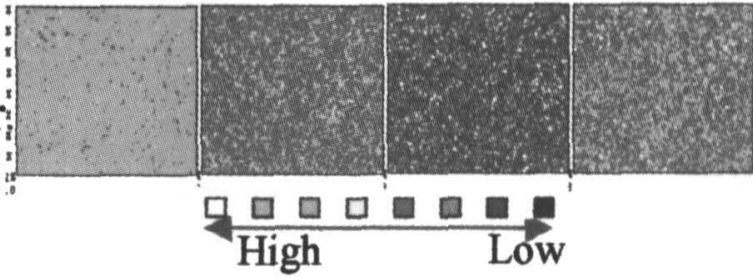

Fig.7 EPMA images of sintered $\mathrm{NiCuZn}$ ferrite. 
ラフ化するために, 解析面積中の原料偏析をバラツキとして 数值化し $\mathrm{CuZn}$ フェライトと $\mathrm{NiCuZn}$ フエライトの混合時間が 及ぼす原料分散度 (Coefficient of variation: 標準偏差 / 平均値) をそれぞれ Fig.8 と Fig.9に示した，図から両フェライトの各 原料は混合時間に伴いC.V 值が低下していることが分かる. また, $\mathrm{Fe}, \mathrm{Ni}, \mathrm{Cu}, \mathrm{Zn}$ の中， Cuが他に比べC.V值が最も高く分 散困難な原料と言える.このCuO原料の混合分散が各フェラ イトの線膨張係数を左右していると考えられる.

次に線膨張係数だけではなく, 原料の混合度が及ぼす磁気 特性への影響を調べた. Fig.9の検討に用いた各試料の $\mu \mathrm{i}$ を測 定した結果をFig.10に示す. 原料混合時間の增加，つまり，原 料の湿合度の向上に伴い $\mu \mathrm{i}$ は增大した。 $\mu \mathrm{i}$ の高い試料は, EPMA 解析の結果からも分かるように原料が均一分散され異 相がない均一なフェライトになっている。 また， $\mu \mathrm{i} か ゙$ 増大し たことは $\mathrm{NiCuZn}$ フェライトを組成的に考えると $\mathrm{ZnO}$ 量が增 加した場合の $\mu \mathrm{i}$ の変化と同じ傾向に見える.

更に,このFig.9に示した各試料について磁歪定数を測定し た. その結果を Fig.11に示すが，原料混合時間の增加に伴い $\mathrm{NiCuZn}$ フェライトの磁歪定数は低下した. $\mathrm{NiCuZn}$ フェライト の $\mathrm{ZnO}$ 量が少なく $\mathrm{NiO}$ 量が多いフェライトは磁歪定数が高く 振動子などに応用されているが，この結果も見かけ上 $\mathrm{ZnO}$ 量

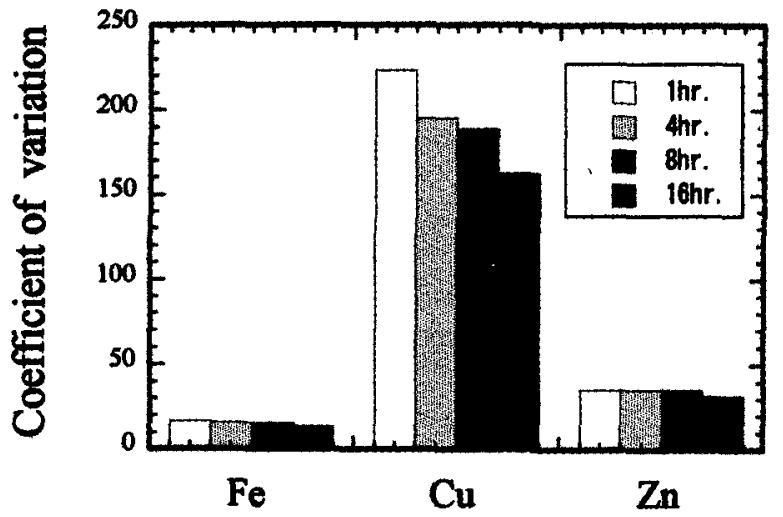

Fig.8 Effect of mixing time on coefficient of variation of $\mathrm{CuZn}$ ferrites.

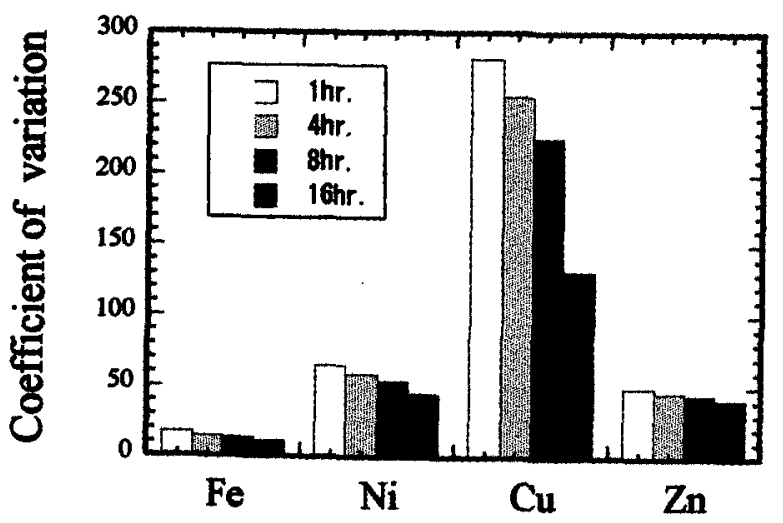

Fig.9 Effect of mixing time on coefficient of variation of $\mathrm{NiCuZn}$ ferrites.
が增加したフェライトの磁歪定数の変化に近い結果になった. これらの結果から,フェライトの線膨張係数の変化について 下記の様に考察した. Fig.4 と Fig.6に示す様に，ZnO 量を增 加させた NiCuZnフェライトは線膨張係数が低下し，また，混 合時間が増加に伴い線膨張伱数は低下した. NiCuZnフェライ トにおいては, $\mathrm{X}$ 線的に $\mathrm{ZnO}, \mathrm{CuO}, \mathrm{NiO}$ の順に固溶していく ことが分かっている7). Fig.4とFig.6の結果はZnOの固溶量が 多く, 未反応もしくは過剩の NiOが少ないほど線膨張係数が 低下したと考えることができる. 更に, その検討では $\mathrm{Fe}_{2} \mathrm{O}_{3}$ お

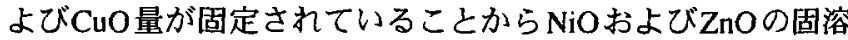
状態，特に過剩酸化物相となりやすい $\mathrm{NiO}$ の影響が大きいと 考えられる.よって, NiCuZn フェライトにおいて CuZn と逆 の結果が得られたものと思われる。

また，セラミックスの熱膨張は原子の熱振動により生じ, 原子間の結合が強いほど熱膨張は小さく，原子間の結合が弱 いほど熱膨張は大きい ${ }^{8}$. 原料混合度を低下させた場合, 固溶 しない酸化物とフェライトスピネル相の複合体と考えられて いる. スピネル結晶の熱振動に加え, 酸化物 (スピネル固溶し ていない原料)とスピネルとの界面の不完全な結合はその熱振 動が大きいと予想させる.このことから, NiCuZnフェライト

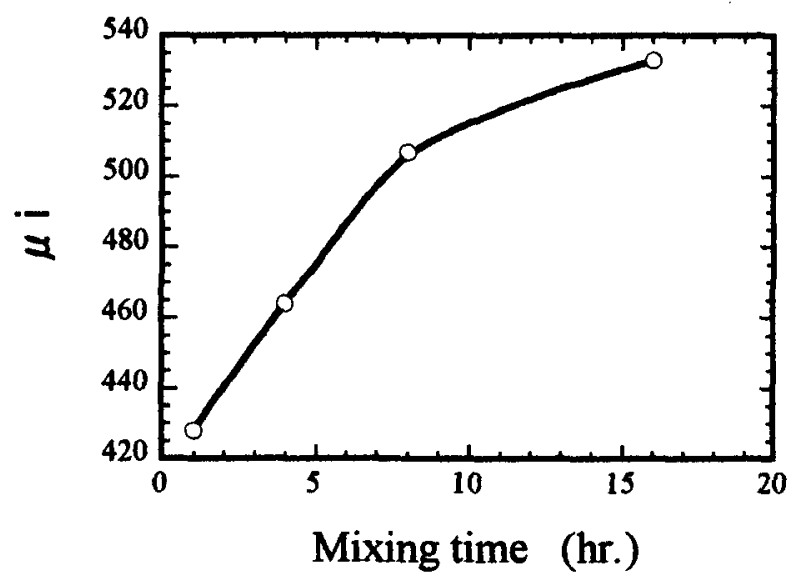

Fig.10 Effect of mixing time on $\mu \mathrm{i}$ of $\mathrm{NiCuZn}$ ferrites.

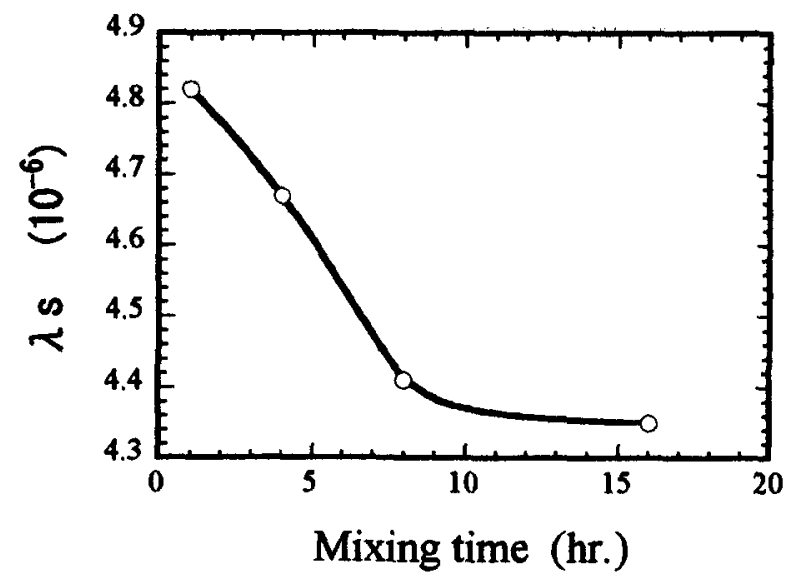

Fig. 11 Effect of mixing time on magnetostriction of $\mathrm{NiCuZn}$ ferrites. 
の原料の混合度が低い試料では線膨張係数が増大し, 混合度 が增加するに伴い線膨張係数が低下したと考えられる.また, $\mathrm{CuZn}$ フェライトの原料混合度の増加に伴い線膨張係数が増大 した結果は，上記のCuO異相等とスピネルとの界面の不完全 な結合の熱振動の影響よりも, Fig.2で示す固溶するCuO量の 増加の影響の方が大きいのではと考えられるが，更なる検討 が必要である.

\section{4 結 論}

低温焼結 NiCuZnフェライトと低温焼結 CuZnフェライトを 同時積層及び同時焼成する積層部品 (MHD など)の高性能化 のために，その両フェライトの線膨張係数の差を減少させる 目的で線膨張係数制御について検討を行い, 以下の結論を得 た.

(1) 非磁性フェライトの低温焼結 $\mathrm{CuZn}$ フェライトの線膨張係 数は, 組成的に $\mathrm{CuO}$ 量, $\mathrm{Fe}_{2} \mathrm{O}_{3}$ 量を增加させることこで増 大した。

(2) 磁性材料の低温焼結 $\mathrm{NiCuZn}$ フェライトの組成と線膨張係 数の関係は, $\mathrm{ZnO}$ 量を增加させて透磁率が高めたフェライ トほど線膨張係数が低下した。

(3) フェライトの原料混合時間の増加に伴い低温焼結 $\mathrm{CuZn}$ フェライトの線膨張係数は增大した.

(4) フェライトの原料混合時間の増加に伴い低温焼結 $\mathrm{NiCuZn}$ フェライトの線膨張係数は低下した．この傾向は CuZn フエライトの結果と正反対であった.

(5) EPMA 解析の結果, フェライトの原料中, 最も $\mathrm{CuO} の$ 分 散が困難であることが判明した。
(6) フェライトの線膨張係数は, 組成で支配されることに加 え, フェライト焼結体中の異相酸化物(スピネル固溶して いない原料)とスピネルとの界面の不完全な結合の熱振動 の影響を受けていると考えられる。

\section{文献}

1) H.Kobuke, A.Nakano, Y.Mochizuki and M.Takaya: "Development of miniaturized DC-DC converter with multilayer ceramic transformer", Proc. of International Symposium on Microelectronics ISHM, (1989)269-274.

2) T.Nomura and A.Nakano: "New evolution of ferrite for multilayer chip components", Proceedings of the 6th international conference on ferrites, (1992) 1198-1201.

3) 中野敦之, 桃井博, 野村武史: " 低温焼結 $\mathrm{NiCuZn}$ フェライ トの微細構造に及ぼす Agの影響",粉体および粉末冶金， 39(1992)612-617.

4) A.Nakano and T.Nomura: "Multilayer Chip Inductors", Ceramic Transactions A. Cer. S., 97(1999)285.

5) 中野, 鈴木, 桃井: " 低温焼結 $\mathrm{NiCuZn}$ フェライトの開発と 積層型チップフェライトの高特性化に関する研究",粉体お よび粉末治金”, 48(2001)131-135.

6) A.Nakano and T.Nomura: "The study of low temperature sintering NiCuZn for multilayer ferrite Chips", Proceedings of the 8th international conference on ferrites, (2000)1117-1121A.

7) 中野, 鈴木, 神奈川, 渡辺, 野村: " 積首型フェライト表面 実装素子", 第 10 回武井セミナ一予稿集, (1990)1-8.

8) セラミックス工学ハンドブック,P14. 